\title{
Electron Transfer of Myoglobin Immobilized in Au Electrodes Modified with a RAFT PMMA-Block-PDMAEMA Polymer
}

\author{
Carla N. Toledo, ${ }^{1}$ Fábio H. Florenzano, ${ }^{2}$ and José M. Schneedorf ${ }^{1}$ \\ ${ }^{1}$ Biochemistry Laboratory, Federal University of Alfenas, R. Gabriel Monteiro da Silva, 700 Centro, 37130-000 Alfenas, MG, Brazil \\ ${ }^{2}$ Engineering School of Lorena, University of São Paulo, Estrada Municipal do Campinho, 12602810 Lorena, SP, Brazil
}

Correspondence should be addressed to José M. Schneedorf; zemasfs@gmail.com

Received 23 May 2014; Revised 8 August 2014; Accepted 12 August 2014; Published 31 August 2014

Academic Editor: Shengshui Hu

Copyright (c) 2014 Carla N. Toledo et al. This is an open access article distributed under the Creative Commons Attribution License, which permits unrestricted use, distribution, and reproduction in any medium, provided the original work is properly cited.

\begin{abstract}
Myoglobin was immobilized with poly(methyl methacrylate)-block-poly[(2-dimethylamino)ethyl methacrylate]PMMA-blockPDMAEMA polymer synthesized by reversible addition-fragmentation chain transfer technique (RAFT). Cyclic voltammograms gave direct and slow quasireversible heterogeneous electron transfer kinetics between Mb-PMMA-block-PDMAEMA modified electrode and the redox center of the protein. The values for electron rate constant $(K s)$ and transfer coefficient $(\alpha)$ were $0.055 \pm 0.01 \cdot \mathrm{s}^{-1}$ and $0.81 \pm 0.08$, respectively. The reduction potential determined as a function of temperature $(293-328 \mathrm{~K})$ revealed a value of reaction center entropy of $\Delta S^{0}$ of $351.3 \pm 0.0002 \mathrm{~J} \cdot \mathrm{mol}^{-1} \cdot \mathrm{K}^{-1}$ and enthalpy change of $-76.8 \pm 0.1 \mathrm{~kJ} \cdot \mathrm{mol}^{-1}$, suggesting solvent effects and charge ionization atmosphere involved in the reaction parallel to hydrophobic interactions with the copolymer. The immobilized protein also exhibits an electrocatalytical response to reduction of hydrogen peroxide, with an apparent $\mathrm{Km}$ of $114.7 \pm 58.7 \mu \mathrm{M}$. The overall results substantiate the design and use of RAFT polymers towards the development of third-generation biosensors.
\end{abstract}

\section{Introduction}

Direct electron transfer of proteins on the surface of bare electrodes is known to present some trouble due to the deep buried of protein redox centers in its structure, as well as adsorptive denaturation and unfavorable orientations of the macromolecule [1]. Several efforts have been made to circumvent this problem, among which are the use of polymer as mediators [2], dimyristoyl phosphatidylcholine [3], polytetrafluoroethylene [4], and poly- $\alpha, \beta-[N-(2-$ hydroxyethyl)-L-aspartamide] films [5]. A different approach to synthesize polymeric structures includes its controlled assembly of functional groups and molecular architectures [6]. There are several controlled/living radical polymerization (CRP) techniques, such as reversible addition-fragmentation chain transfer or RAFT polymerization [7]. RAFT technique uses a chain transfer compound to attain control over the molecular weight and polydispersity during a free-radical polymerization, resulting in well-defined polymers, as well as diblock, triblock, and polymers with more complex architectures [8]. RAFT polymers have attracted considerable attention in the last decade, toward to a broad spectrum of applications including optoelectronics, block copolymer therapeutics, and star polymer rheology control agents [9]. In this regard, several derivatives of diblock RAFT polymers such as poly(methyl methacrylate)block-poly[(2-dimethylamino) ethyl methacrylate](PMMA$b$-PDMAEMA) have been used due to their versatility, stability, and ease of processing [10]. As some RAFT polymers seem to exhibit electroactivity $[11,12]$, they would be also used for entrapment of macromolecules under electrochemical investigation. Keeping this in mind, the aim of this work was to investigate the redox properties of myoglobin immobilized in PMMA-block-PDMAEMA, as a feasible approach to the development of a third-generation biosensor.

\section{Material and Methods}

2.1. Chemicals. Horse myoglobin ( $\mathrm{Mb}, \mathrm{MW} 17,800)$ and methylmethacrylate, 99\%, were purchased from SigmaAldrich. 2-(dimethylamino) ethyl methacrylate (DMAEMA, $98 \%$, Sigma-Aldrich) was used with no further purification. 
Benzoyl peroxide (BPO) and glutaraldehyde was obtained from Vetec Brazil and used as received. Phosphate buffer solutions were prepared by adjusting the $\mathrm{pH}$ values either with $0.1 \mathrm{M} \mathrm{NaOH}$ or $0.1 \mathrm{M} \mathrm{HCl}$. All other chemical reagents were of analytical grade and all the solutions were prepared with Milli-Q water.

2.2. Copolymer Synthesis. The RAFT technique was used for the synthesis of PMMA- $b$-PDMAEMA copolymers. The chain transfer agent used was cumyl dithiobenzoate (CDB), previously synthesized according to a modified two-step method by Mertoglu [13]. First the synthesis of dithiobenzoic acid is carried out followed by the addition of $\alpha$ methylstyrene to the acid. The synthesis was started by the PMMA block, using benzoyl peroxide (BPO) as initiator. The PMMA blocks were purified by precipitation in methanol and drying in vacuum. These PMMA blocks were afterwards used as macrochain transfer agents (macroCTA) in a copolymerization using DMAEMA as monomer and BPO as initiator. The copolymers were purified by precipitation in n-hexane. Products were confirmed by $1 \mathrm{H}-\mathrm{NMR}$ (INOVA DPX 300 Bruker spectrometer). All copolymers produced visually homogeneous aqueous solutions at neutral and low $\mathrm{pHs}$. Precipitation occurs within the $\mathrm{pH}$ range of 9-10 at $25^{\circ} \mathrm{C}$. Lower critical solution temperature (LCST) for all copolymers at $\mathrm{pH}=7.0$ is above $40^{\circ} \mathrm{C}$.

2.3. Electrode Preparation. After electrode cleaning, $30 \mu \mathrm{L}$ of a stock solution of PMMA- $b$-PDMAEMA $10 \mathrm{mg} \cdot \mathrm{mL}^{-1}$ in acetone was pipetted on the electrode surface following evaporation for $4 \mathrm{~h}$ at room temperature. Then, $30 \mu \mathrm{L}$ of myoglobin $(\mathrm{Mb})$ at $5 \mathrm{mg} \cdot \mathrm{mL}^{-1}$ was carefully dripped onto the electrode surface. After $4 \mathrm{~h}$, the electrode was rinsed again to remove adsorbed protein, followed by pipetting glutaraldehyde $2 \%$ for $30 \mathrm{~min}$. After washing, the electrode was rinsed with water and dried in nitrogen atmosphere prior to electrochemical experiments. When not in use, the sensor was stored in nitrogen-saturated buffer solution $(\mathrm{pH} \mathrm{7.5)}$ at room temperature in the dark.

2.4. Cyclic Voltammetry. Cyclic voltammetry (CV) was performed using a potentiostat PG39MCSV (Omni Metra Instrumentos Científicos Ltda, RJ, Brazil). A conventional three-electrode system was used with bare or modified homemade gold electrode (4 mm diameter, 99.9\% purity, SigmaAldrich) as the working electrode, $\mathrm{Ag} / \mathrm{AgCl}$ as the reference electrode, and a platinum wire as the counter electrode. Gold electrode was first polished using aqueous slurries of $10 \mu \mathrm{m}$ alumina, placed in ethanol (99.5\%), and subjected to ultrasonic vibration to remove residual alumina particles. Finally, the electrode was etched for $2 \mathrm{~min}$ in a hot Piranha solution $\left(1: 3(\mathrm{v} / \mathrm{v}) 30 \% \mathrm{H}_{2} \mathrm{O}_{2}\right)$ and concentrated $\left.\mathrm{H}_{2} \mathrm{SO}_{4}\right)$ and then rinsed with copious amounts of ultrapure Millipore water followed by ethanol washing.

2.5. Thermodynamic Assays. The temperature dependence of the reduction potential was determined with a nonisothermal cell [14] in which the reference electrode is kept at constant temperature, while the temperature of the working electrode is varied. For such an experimental setting, the values for standard entropy $\left(\Delta S^{0}\right)$ and enthalpy $\left(\Delta H^{0}\right)$ changes of the reaction center upon reduction wer obtained from the relation below [15]:

$$
\begin{gathered}
\Delta S^{0}=n F\left(\frac{d \Delta E^{0}}{d T}\right), \\
\Delta H^{0}=-n F\left(\frac{d \Delta E^{0} / T}{d(1 / T)}\right) .
\end{gathered}
$$

2.6. Electroactivity against Hydrogen Peroxide. Amperometric measurements were performed under unstirred conditions. Aliquots of standard solution of $\mathrm{H}_{2} \mathrm{O}_{2}$ (10$480 \mu \mathrm{mol} \cdot \mathrm{L}^{-1}$ ) were added to the buffer solution. Prior to the experiments, buffer and sample solutions were purged with pure nitrogen for $10 \mathrm{~min}$ to remove oxygen.

2.7. Data Analysis. All of the experiments were conducted in triplicate. The data were expressed as mean \pm standard error. Adjustments of equations to the data were performed with $\mathrm{R}$ (R Core Development Team) [16].

\section{Results and Discussion}

3.1. Cyclic Voltammetry. The prosthetic group of $\mathrm{Mb}$ contains an iron atom in heme system, and the charge transfer of $\mathrm{Mb}$ is based on the ferric reduction inside this porphyrin ring system. The cyclic voltammograms for Mb/PMMA$b$-PDMAEMA modified electrode in $0.1 \mathrm{~mol} \cdot \mathrm{L}^{-1}$ phosphate buffer $\mathrm{pH} 7.4$ can be viewed in Figure 1. A pair of well-defined, quasireversible $\mathrm{CV}$ redox peaks centered at about 50 and $200 \mathrm{mV}$, for cathodic and anodic wave peaks, respectively, can be observed (Figure 1(b)). The electrode modified with PMMA-block-PDMAEMA also showed a small contribution to the faradaic current in the buffer solution, which seems to persisted even with the entrapped protein. Although the proper mechanism of charge transfer between the Au surface and the modified electrode without myoglobin is not clear, the copolymer itself may have contributed to the shoulder peak presented in the CV results [17].

The ipa/ipc ratio, an index of reversibility of electron transfer, was found to be $0.84 \pm 0.08$ with varying scanning rates (Figure 3). Furthermore, a log-log plot of scan rates against anodic peak potentials resulted in slope value of $0.72 \pm$ 0.05 , far from 0.5 expected from a pure diffusional process of electron transfer $\left(R^{2}=0.948\right)$.

The effect of scanning rate on the response of the $\mathrm{Mb} / \mathrm{PMMA}-b$-PDMAEMA modified electrode is present in Figures 2 and 3 . The height of reduction peak current was linearly proportional to the square root of the scan rates in the range of $20-500 \mathrm{mV} \cdot \mathrm{s}^{-1}\left(R^{2}=0.961\right)$, although the oxidation peak current revealed a deviation from the linear trend $\left(R^{2}=\right.$ $0.784)$. These findings suggest the characterisation of surface or thin layer electrochemistry on the electrode surface [18, 


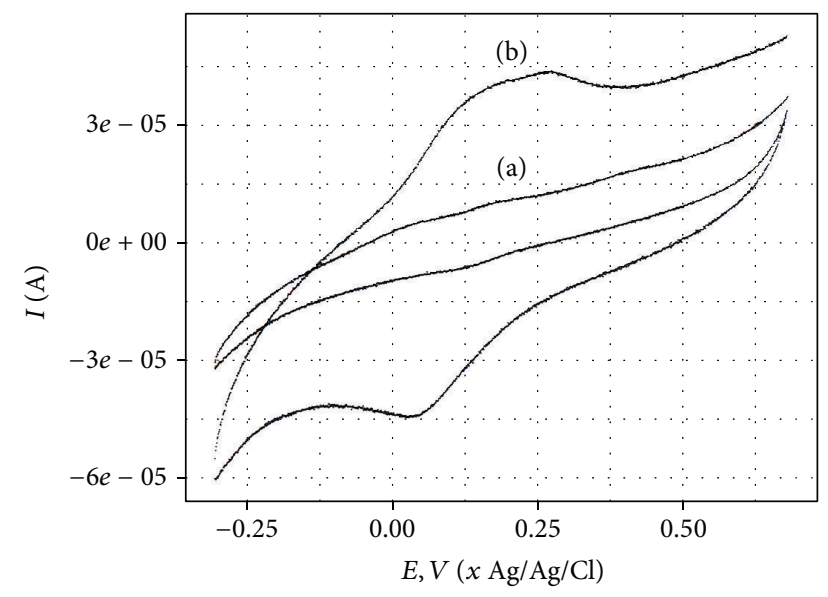

FIgUre 1: Cyclic voltammograms of Au electrode modified with PMMA- $b$-PDMAEMA (a) and Mb/PMMA- $b$-PDMAEMA (b) in $0.1 \mathrm{~mol} \cdot \mathrm{L}^{-1}$ sodium phosphate buffer solution $(\mathrm{pH} 7.45)$. Scan rate: $100 \mathrm{mV} / \mathrm{s}$.

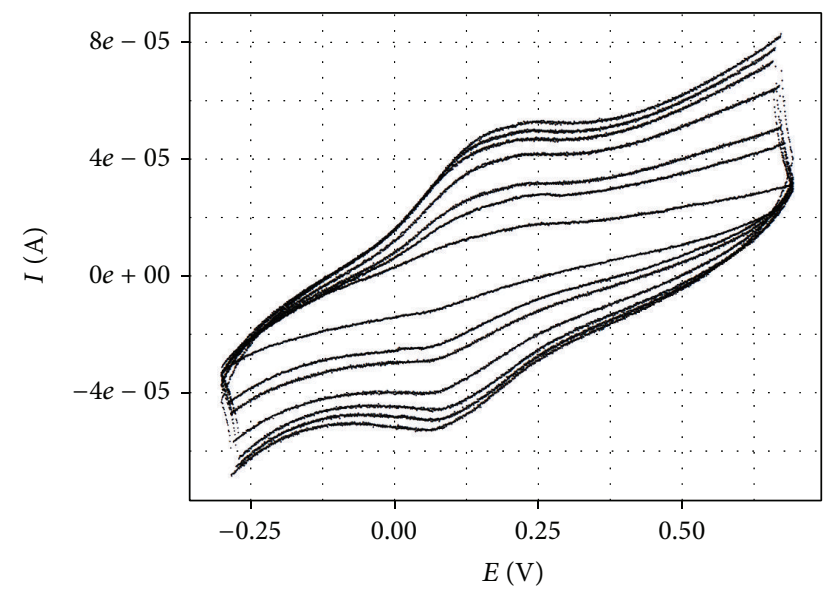

FIGURE 2: Cyclic voltammogram of Mb/PMMA- $b$-PDMAEMA in phosphate buffer at different scan rates $(20-500 \mathrm{mV} / \mathrm{s})$.

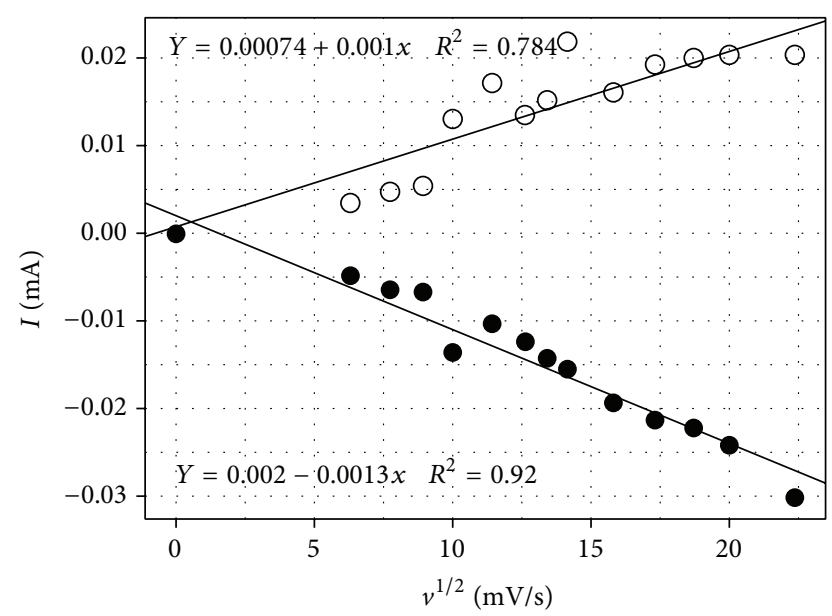

FIGURE 3: Variation of CV anodic peak current with the scan rate for Mb/PMMA- $b$-PDMAEMA in phosphate buffer. Symbols represent anodic and cathodic data: $\bigcirc-\mathrm{ip}_{a}$ and $-\mathrm{ip}_{c}$ data.
19]. The surface concentration of the electroactive protein $(\Gamma)$ was further estimated following Laviron [20]:

$$
I p=\frac{n^{2} F^{2} \nu A \Gamma}{4 R T}
$$

where $F$ is the Faraday constant; $\Gamma$ is the surface concentration of the electroactive substance; $A$ is the geometric area of the electrode; $v$ is the scan rate; and $n$ is the number of electrons transferred. Under the condition of saturated adsorption, the average surface coverage of electroactive $\mathrm{Mb}$ was about $1.94 \times$ $10^{-11} \mathrm{~mol} \cdot \mathrm{cm}^{-2}$. This surface concentration changed slightly with scan rates from 1.5 to $3.5 \times 10^{-11} \mathrm{~mol} \cdot \mathrm{cm}^{-2}$, in agreement to a surface-confined process on the modified electrode $[19,20]$. This value was close to the reported elsewhere for chitosan films [21] and modified carbon nanotube electrodes [22] and greater than $1.58 \times 10^{-11} \mathrm{~cm}^{-2}$ expected for a monolayer of myoglobin adsorbed onto metallic electrode surfaces [23]. In addition, the modified electrode retained $89 \%$ of its surface concentration up to 21 days.

In this sense, myoglobin molecules could be embedded in PMMA- $b$-PDMAEMA di-block on the modified electrode. In fact, the copolymer has a molecular mass of $66.1 \mathrm{~kg} \cdot \mathrm{mol}^{-1}$ [24] and hydrodynamic radius of 2,2 $\mathrm{nm}$ [25]), values larger than those found for $\mathrm{Mb}\left(17.5 \mathrm{~kg} \cdot \mathrm{mol}^{-1}\right.$ [26] and $0.21 \mathrm{~nm}$ [27], resp.). Moreover, a linear length of $92 \AA$ for the outstretched copolymer can be hypothesized, considering the individual molecular mass of the blocks (100.12 g. mol ${ }^{-1}$ and $157.21 \mathrm{~g} \cdot \mathrm{mol}^{-1}$ for MMA and DMAEMA, resp.) and their polymerization degree (5400 and 60700, resp.). In this sense, a plausible thickness for the copolymer on the electrode surface can be calculated from the value of double layer capacitance resulted following Asaka [28], (3), and (4) [29]:

$$
\frac{i_{a}-i_{c}}{2}=C_{\mathrm{dl}} \cdot v,
$$

where $i_{a}$ e $i_{c}$ represent, respectively, the anodic and cathodic current estimated from the central part of the cyclic voltammogram (Figure 1, after baseline correction). Therefore, the thickness $d$ can be computed by

$$
C_{\mathrm{dl}}=\frac{\varepsilon_{0} \cdot \kappa}{d},
$$

where $C_{\mathrm{dl}}$ represents the double layer capacitance of the adsorbed copolymer and $\varepsilon_{0}$ the electrical permittivity of free space $\left(8.85 \cdot 10^{-12} \mathrm{~F} \cdot \mathrm{m}^{-1}\right.$, and $\kappa$ the dielectric constant of the copolymer (PMMA, 1.08 [30]). The capacitance $C_{\mathrm{dl}}$ was determined from the current difference between the forward and reverse scans, following (3) [28]. From (4), a thickness of $180 \mathrm{~nm}$ was found for the PMMA- $b$-PDMAEMA on the electrode surface. Even with this roughly estimated value for the diblock thickness, a multilayer structure for the copolymer coverage can be suggested [19].

Figure 2 shows that with the increase of the scan rate, the redox peak potentials were also shifted gradually. In order to obtain information on the rate-determining step, Tafel slope was determined from the relationship between $\log v$ 


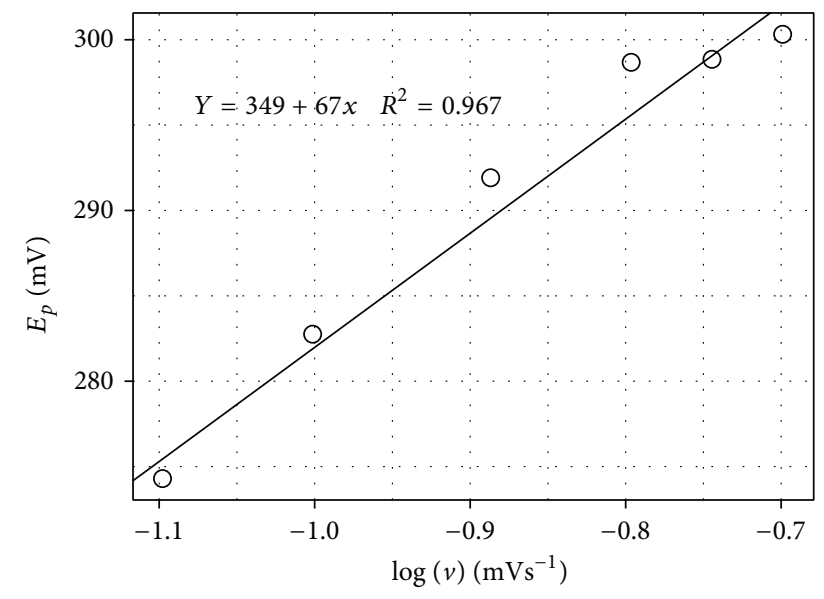

FIGURE 4: Tafel plot derived from the rising part of anodic voltammogram for Mb/PMMA- $b$-PDMAEMA electrode.

versus $E_{p}$ [31], by taking the rising part of the voltammograms (Figure 2) as follows [32]:

$$
E_{p a}=E^{0}+\frac{R T}{(1-\alpha) n F} \cdot \log v .
$$

From Tafel slope in Figure 4, the electron transfer coefficient $\alpha$ was calculated as $0.81 \pm 0.08$. According to (6) for $\Delta E_{p}>200 \mathrm{mV}$ [18], the electron rate constant was found to be $0.055 \pm 0.01 \cdot \mathrm{s}^{-1}$. Consider

$$
\begin{aligned}
\log (k s)= & \alpha \log (1-n \alpha)+(1-\alpha) \log n \alpha-\log \frac{R T}{n F \nu} \\
& -(1-\alpha) \alpha n F \frac{\Delta E_{p}}{2.303 R T} .
\end{aligned}
$$

Both $\alpha$ and $k s$ values agree well with a quasireversible process in Mb-modified electrode [33], but revealed a slower degree for the electron transfer rate than that reported for the entrapped protein $[1,31]$.

Cyclic voltammetry was also used to investigate the $\mathrm{pH}$ dependence of the formal potentials which were calculated from the midpoint of reduction and oxidation peak potentials for the Mb/PMMA- $b$-PDMAEMA modified electrode. As the copolymers can form aggregates below $\mathrm{pH} 4.0$ and solubilize in aqueous medium above $\mathrm{pH} 7.5$ (isoelectric point around 8$9[10,34]), \mathrm{pH}$ values varied from 4.5 to 7.5 . The results are presented in Figure 5.

All changes in voltammogram peak potentials with $\mathrm{pH}$ were reversible in the range tested ( $\mathrm{pH} 4.5$ to 7.5). A cathodic shift in $E^{0}$ values was found with increasing $\mathrm{pH}$, suggesting a decrease in dielectric constant medium and/or an ionization of the protein surface [35]. The linear relationship of $E^{0}$ with $\mathrm{pH}$ from 4.5 to 7.5 exhibited a slope of $-0.026 \pm$ $0.0018 \mathrm{pH} / \mathrm{V}$. Nearly, the same slope value has been found at glassy carbon electrode modified with myoglobin entrapped with the cationic surfactant didodecyldimethylammonium [36]. These slope values can be expected for a Nernstian behavior from a charge transfer with two electrons coupled a participation of one $\mathrm{H}^{+}$[37]. Nevertheless, myoglobin exhibit

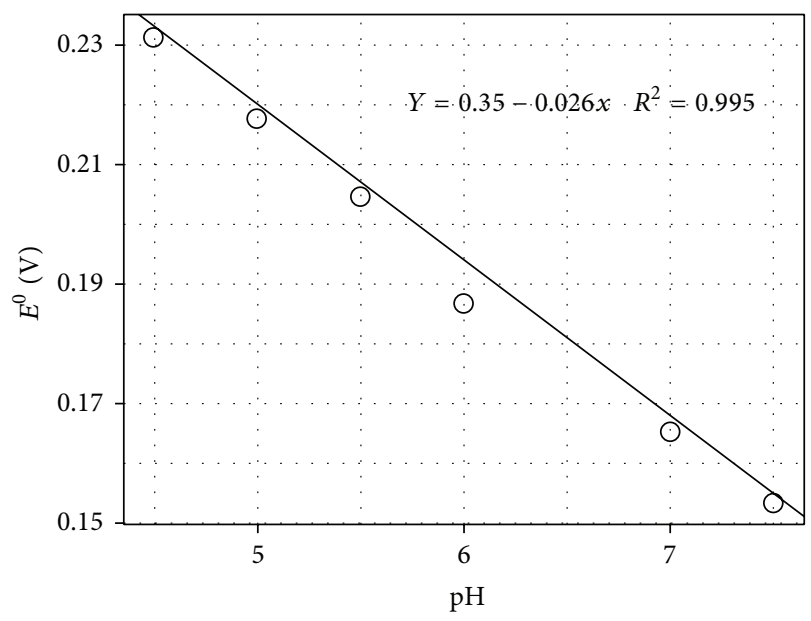

FIgURE 5: $\mathrm{pH}$ dependence on the formal potential for Mb/PMMA$b$-PDMAEMA electrode in phosphate buffer. Scan rate: $100 \mathrm{mV} / \mathrm{s}$.

a single proton transfer coupled to the electron transfer reaction [1,31]. Although this finding has not yet been conclusive and needs further research, both PDMAEMA monomer [38] and didodecyldimethylammonium ion have a cationic amine positively charged at the $\mathrm{pH}$ assayed [34]. Hence, it can be speculated that the positively charged state of tertiary amines of the PDMAEMA can play a role on the overall electron-transfer mechanism resulting in the slope value far below than that theoretically expected.

As the pI value for $\mathrm{Mb}$ is known to be 6.8 [39], it is reasonable to believe the existence of an anionic atmosphere around the metallic group on the protein at the $\mathrm{pH}$ assayed, favouring an electrostatic interaction with the porphyrin ring system. The PMMA-block-PDMAEMA polymer has a pKa value around 8 , depending on the side chain conformation [10], suggesting a positively charged state for their tertiary amines. Keeping this in mind, an electrostatic interaction could be taking place between the RAFT copolymer and the protein molecule, parallel to hydrophobic forces, enhancing the strength for the complex.

3.1.1. Redox Thermodynamics of Mb/PMMA-b-PDMAEMA. Using the cell/electrode assembly described at the 2.5 item, voltammetric nonisothermal determination for entropy $\left(\Delta S^{0}\right)$ and enthalpy $\left(\Delta H^{0}\right)$ of redox process occurring on the Mb/PMMA- $b$-PDMAEMA modified electrode was accomplished. The redox thermodynamics was done following Tanigushi and coworkers [14], increasing the temperature of the electrochemical cell from 293 to $328 \mathrm{~K}$.

From Figure 6, a reaction center entropy change $\left(\Delta S^{0}\right)$ of $351.3 \pm 0.0002 \mathrm{~J} \cdot \mathrm{mol}^{-1} \cdot \mathrm{K}^{-1}$ was calculated for the Mb/PMMA$b$-PDMAEMA. From the Gibbs-Helmholtz relationship obtained from a plot of $E / T$ versus $1 / T$ (Figure 7), the enthalpy change $\left(\Delta H^{0}\right)$ was $-76831.9 \pm 0.8 \mathrm{~J} \cdot \mathrm{mol}^{-1}$.

The reduction entropy appeared to be affected by solvation properties, namely, the reducing-induced reorganization of solvent molecules bound onto the protein surface near the iron center [40]. The value of $\Delta S^{0}$ for $\mathrm{Mb}$ is higher than that 


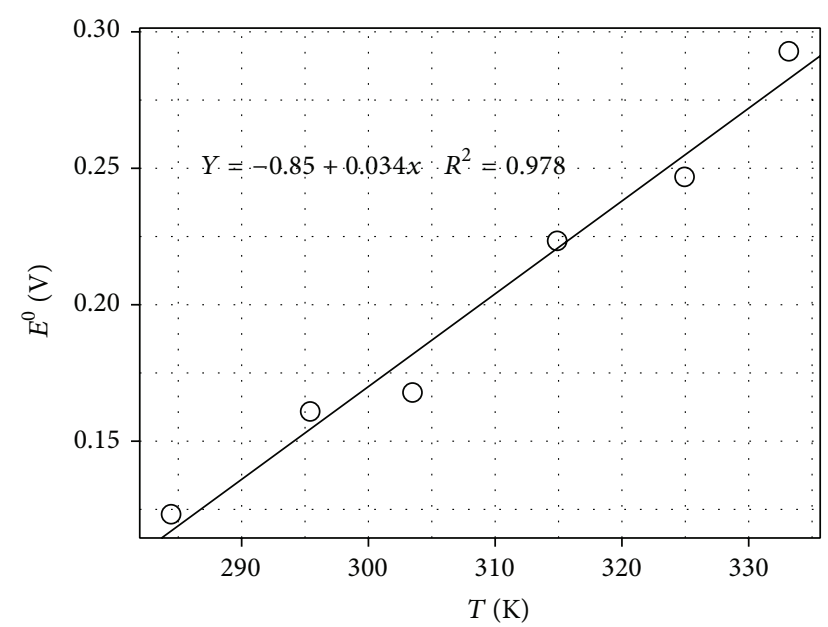

FIGURE 6: Temperature dependence of the redox potential of $\mathrm{Mb} / \mathrm{PMMA}-b$-PDMAEMA in phosphate buffer.

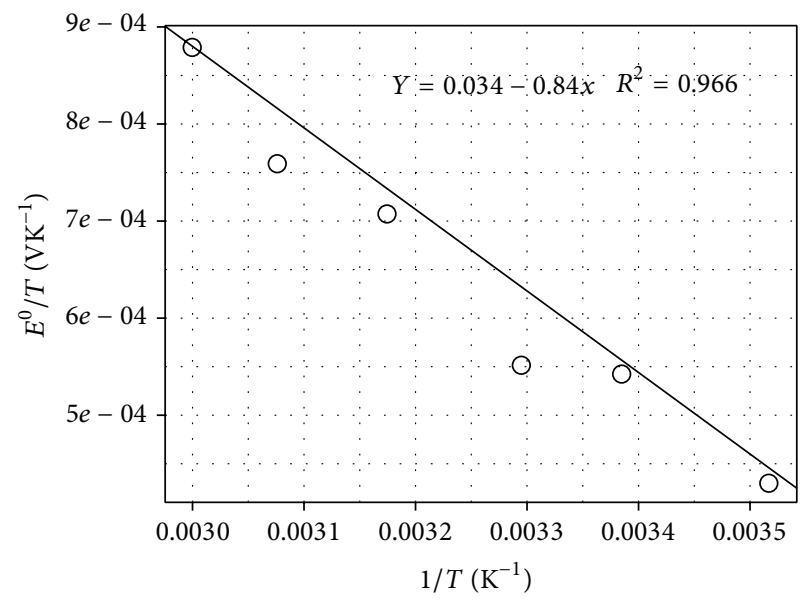

FIgURE 7: Gibbs-Helmholtz plot for Mb/PMMA- $b$-PDMAEMA in phosphate buffer.

reported in aqueous solution [41]. On the other hand, the remarkable negative value for the enthalpy change indicated that the electron transfer reactions are exothermic and all the oxidized protein can approach more flexible polypeptide conformation at higher temperatures [42]. This $\Delta H^{0}$ value can be also ascribed to the stabilization of the ferroheme by ligand binding interactions and the hydrophobicity of the heme environment [35]. As a whole, this temperature dependence of the redox potential for Mb/PMMA- $b$-PDMAEMA seems to reflect changes in the protein structure, together with its interactions with the solvent, with PMMA- $b$-PDMAEMA, or with a combination of these effects. Notwithstanding, conformational changes in the $\mathrm{Mb}$ structure can be discarded, as no inflection point can be observed in Figure $6[43,44]$.

3.2. Electrocatalytic Activity. Although the proper mechanism of charge transfer remains unclear in this work, a catalytic activity of Mb/PMMA- $b$-PDMAEMA modified electrode was tested against the reduction of $\mathrm{H}_{2} \mathrm{O}_{2}$. When

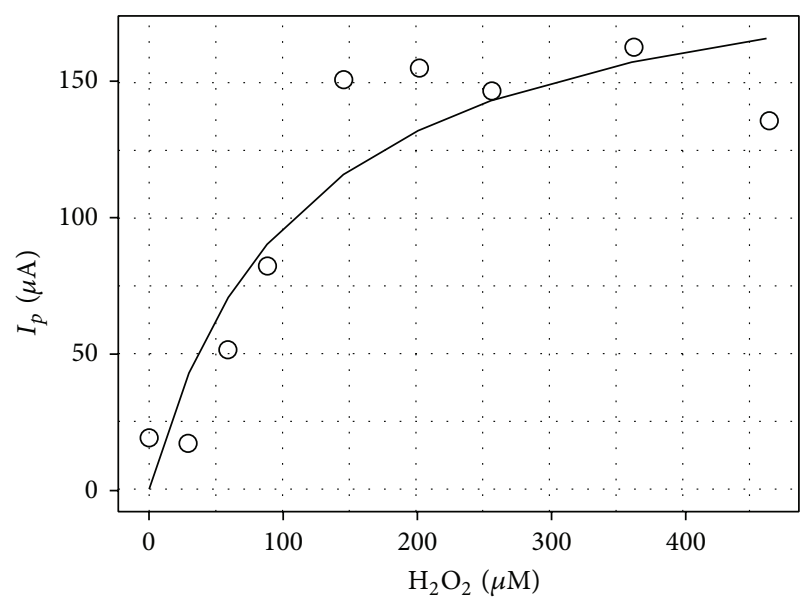

Figure 8: Michaelis-Menten representation of the amperometric response of catalytic activity of Mb/PMMA- $b$-PDMAEMA against $\mathrm{H}_{2} \mathrm{O}_{2}$ in phosphate buffer.

hydrogen peroxide was added to the buffer solution at $\mathrm{pH} 7.5$, an increase in the current value for the reduction peak could be observed (Figure 8). A reference test in absence of $\mathrm{Mb}$ did not show any catalytic activity for $\mathrm{H}_{2} \mathrm{O}_{2}$. From Figure 8, an apparent $\mathrm{Km}$ value for the Michaelis-Menten behavior was determined as follows:

$$
I_{\mathrm{ss}}=\frac{I_{\max } \cdot\left[\mathrm{H}_{2} \mathrm{O}_{2}\right]}{K m+\left[\mathrm{H}_{2} \mathrm{O}_{2}\right]}
$$

where $I_{\max }$ is the maximum current measured under saturated substrate conditions. The apparent $K m$ value was found to be $114.7 \pm 58.7 \mu \mathrm{M}$, close to the reported elsewhere for $\mathrm{Mb}$ modified electrodes [31, 45], and smaller than that presented for $\mathrm{Hb} /$ sol-gel film modified CPE [46]. This value for $\mathrm{Km}$ also indicates that the immobilized $\mathrm{Mb}$ has a high biological affinity to $\mathrm{H}_{2} \mathrm{O}_{2}$.

3.3. Mechanism Proposed for Mb/PMMA-b-PDMAEMA. As stated by Gohy et al. [34], PDMAEMA can be partially charged in aqueous medium in $7<\mathrm{pH}<10$ range, resulting in a surfactant behaviour that can lead to aggregation and micelle formation [47]. So, a hydrophobic effect can be occurring at the $\mathrm{pH} 7.4$ assayed, enhancing the interaction of PMMA- $b$-PDMAEMA with the gold electrode surface. This hydrophobic effect may also be improved by the Mbembedded multilayer nature of PMMA- $b$-PDMAEMA, as suggested above.

The tertiary structure of myoglobin is made up of seven alpha helical segments. As sequences that form surfaceseeking helices have large hydrophobic dipole moments [48], it is plausible to believe that a large portion of hydrophobic area can contribute to the copolymer binding due to their benzoyl and ethylene groups, in addition to the heme binding pocket.

Moreover, the copolymer diblock has several oxygen ether groups of high electronegativity in its methyl/ethyl methacrylate moieties which could lead to an ion-dipole attraction between oppositely charged of these groups with 
Lys and Arg residues on the $\mathrm{Mb}$ surface. In fact, $\mathrm{Mb}$ has 19 Lys and 2 Arg residues exposed to the solvent, and with pKa values of 10-12 and 12-13, respectively [49], thus offering positively exposed charges on the protein surface. This hypothesis is in agreement with similar ion-dipole interaction reported for electrochemical adsorption systems of proteins with polyelectrolytes $[50,51]$. Then, the combined electrostatic (anionic $\mathrm{Mb} /$ cationic copolymer), iondipole (Lys, Arg/oxygen ether for the copolymer), hydrophobic interactions, and hydrogen bonding between myoglobin and PMMA- $b$-PDMAEMA (and also the hydrophobic effect between the gold electrode surface and PMMA- $b$ PDMAEMA) could provide the major driven forces for the stabilization of Mb/PMMA- $b$-PDMAEMA at the electrode surface.

\section{Conclusion}

We have tested the use of a RAFT polymer for electrochemical studies of myoglobin as a model protein. As this polymerization approach for block synthesis allows very precise control over the polymerization process while retaining much of the versatility of conventional radical polimerization, newer copolymers can be reached as a function of specific goals for direct protein electrochemistry and towards the development of newer biosensors with desired specifications.

\section{Conflict of Interests}

The authors declare that there is no conflict of interests regarding the publication of this paper.

\section{Acknowledgment}

The authors acknowledge the Minas Gerais State Research Foundation-FAPEMIG for Grant no. CBB-APQ-01920-11 that supported this work.

\section{References}

[1] Y. Xie, N. Hu, and H. Liu, "Bioelectrocatalytic reactivity of myoglobin in layer-by-layer films assembled with triblock copolymer Pluronic F127," Journal of Electroanalytical Chemistry, vol. 630, no. 1-2, pp. 63-68, 2009.

[2] E. Ferapontova, S. Shleev, T. Ruzgas, and L. Stoica, "Direct electrochem istry of proteins and enzymes," in Electrochemistry of Nucleic Acids and Proteins towards Electrochemical Sensors for Genomics and Proteomics, F. S. E. Paleek and J. Wang, Eds., vol. 1 of Perspectives in Bioanalysis, pp. 517-598, Elsevier, New York, NY, USA, 2005.

[3] J. Yang and N. Hu, "Direct electron transfer for hemoglobin in biomembrane-like dimyristoyl phosphatidylcholine films on pyrolytic graphite electrodes," Bioelectrochemistry and Bioenergetics, vol. 48, no. 1, pp. 117-127, 1999.

[4] Q. $\mathrm{Lu}$ and S. Hu, "Studies on direct electron transfer and biocatalytic properties of hemoglobin in polytetrafluoroethylene film," Chemical Physics Letters, vol. 424, no. 1-3, pp. 167-171, 2006.
[5] Q. Lu, T. Zhou, and S. Hu, "Direct electrochemistry of hemoglobin in PHEA and its catalysis to $\mathrm{H}_{2} \mathrm{O}_{2}$," Biosensors and Bioelectronics, vol. 22, no. 6, pp. 899-904, 2007.

[6] N. Badi and J. Lutz, "Sequence control in polymer synthesis," Chemical Society Reviews, vol. 38, no. 12, pp. 3383-3390, 2009.

[7] A. B. Lowe and C. L. McCormick, "Reversible additionfragmentation chain transfer (RAFT) radical polymerization and the synthesis of water-soluble (co)polymers under homogeneous conditions in organic and aqueous media," Progress in Polymer Science, vol. 32, no. 3, pp. 283-351, 2007.

[8] G. Moad, E. Rizzardo, and S. H. Thang, "RAFT polymerization and some of its applications," Chemistry, vol. 8, no. 8, pp. 1634$1644,2013$.

[9] G. Moad, E. Rizzardo, and S. H. Thang, "Living radical polymerization by the RAFT process A second update," Australian Journal of Chemistry, vol. 62, no. 11, pp. 1402-1472, 2009.

[10] J. C. P. de Souza, A. F. Naves, and F. H. Florenzano, "Specific thermoresponsiveness of PMMA-block-PDMAEMA to selected ions and other factors in aqueous solution," Colloid and Polymer Science, vol. 290, no. 13, pp. 1285-1291, 2012.

[11] C. D. Grande, M. C. Tria, M. J. Felipe, F. Zuluaga, and R. Advincula, "RAFT "grafting-through" approach to surface-anchored polymers: electrodeposition of an electroactive methacrylate monomer.", The European physical journal E: Soft matter, vol. 34, no. 2, pp. 1-10, 2011.

[12] H. Kakwere and S. Perrier, "Design of complex polymeric architectures and nanostructured materials/hybrids by living radical polymerization of hydroxylated monomers," Polymer Chemistry, vol. 2, no. 2, pp. 270-288, 2011.

[13] M. Mertoglu, The synthesis of well-defined functional homoand block copolymers in aqueous media via reversible additionfragmentation chain transfer (raft) polymerization [M.S. thesis], Post-dam University, 2004.

[14] V. T. Taniguchi, N. Sailasuta-Scott, F. C. Anson, and H. B. Gray, "Thermo- dynamics of metalloprotein electron transfer reactions," Pure and Applied Chemistry, vol. 52, pp. 2275-2281, 1980.

[15] E. T. Smith, J. M. Blamey, Z. H. Zhou, and M. W. W. Adams, "A variable-temperature direct electrochemical study of metalloproteins from hyperthermophilic microorganisms involved in hydrogen production from pyruvate," Biochemistry, vol. 34, no. 21, pp. 7161-7169, 1995.

[16] R Development Core Team, R: A Language and Environment for Statistical Computing, Foundation for Statistical Computing, Vienna, Austria, 2012.

[17] W. Guo and N. Hu, "Interaction of myoglobin with poly(methacrylic acid) at different $\mathrm{pH}$ in their layer-bylayer assembly films: an electrochemical study," Biophysical Chemistry, vol. 129, no. 2-3, pp. 163-171, 2007.

[18] E. Laviron, "The use of linear potential sweep voltammetry and of a.c. voltammetry for the study of the surface electrochemical reaction of strongly adsorbed systems and of redox modified electrodes," Journal of Electroanalytical Chemistry, vol. 100, no. 1-2, pp. 263-270, 1979.

[19] M. Noel and K. I. Vasu, "Cyclic voltammetr y and the frontiers of electro chemistry," Aspect, 1990.

[20] E. Laviron, "General expression of the linear potential sweep voltammogram in the case of diffusionless electrochemical systems," Journal of Electroanalytical Chemistry, vol. 101, no. 1, pp. 19-28, 1979. 
[21] H. Huang, N. Hu, Y. Zeng, and G. Zhou, "Electrochemistry and electrocatalysis with heme proteins in chitosan biopolymer films," Analytical Biochemistry, vol. 308, no. 1, pp. 141-151, 2002.

[22] M. J. Esplandiu, M. Pacios, L. Cyganek, J. Bartroli, and M. del Valle, "Enhancing the electrochemical response of myoglobin with carbon nanotube electrodes," Nanotechnology, vol. 20, no. 35, Article ID 355502, 2009.

[23] H. Liu, Z. Tian, Z. Lu, Z. Zhang, M. Zhang, and D. Pang, "Direct electrochemistry and electrocatalysis of heme-proteins entrapped in agarose hydrogel films," Biosensors and Bioelectronics, vol. 20, no. 2, pp. 294-304, 2004.

[24] V. V. de Souza, M. L. D. C. Noronha, F. L. A. Almeida, C. A. R. Prado, A. C. Doriguetto, and F. H. Florenzano, "Cmc of PMMAblock-PDMAEMA measured by NPN fluorescence," Polymer Bulletin, vol. 67, no. 5, pp. 875-884, 2011.

[25] F. L. Baines, S. P. Armes, N. C. Billingham, and Z. Tuzar, "Micellization of poly(2-(dimethylamino)ethyl methacrylate-blockmethyl methacrylate) copolymers in aqueous solution," Macromolecules, vol. 29, no. 25, pp. 8151-8159, 1996.

[26] S. Nakao, H. Osada, H. Kurata, T. Tsuru, and S. Kimura, "Separation of proteins by charged ultrafiltration membranes," Desalination, vol. 70, no. 1-3, pp. 191-205, 1988.

[27] D. K. Wilkins, S. B. Grimshaw, V. Receveur, C. M. Dobson, J. A. Jones, and L. J. Smith, "Hydrodynamic radii of native and denatured proteins measured by pulse field gradient NMR techniques," Biochemistry, vol. 38, no. 50, pp. 16424-16431, 1999.

[28] K. Asaka, A. Ottova, and H. T. Tien, "Mediated electron transfer across supported bilayer lipid membrane (s-BLM)," Thin Solid Films, vol. 354, no. 1, pp. 201-207, 1999.

[29] L. Du, X. Liu, W. Huang, and E. Wang, "A study on the interaction between ibuprofen and bilayer lipid membrane," Electrochimica Acta, vol. 51, no. 26, pp. 5754-5760, 2006.

[30] M. Madani, S. S. Aly, and S. M. El-Sayed, "Dielectric relaxation of new aniline methyl methacrylate copolymer synthesized by gamma irradiation initiated polymerization," High Performance Polymers, vol. 22, no. 5, pp. 515-533, 2010.

[31] J. Huang, J. Zheng, and Q. Sheng, "Direct electrochemistry of myoglobin based on electrodeposition of Pd nanoparticles with carbon ionic liquid electrode as basic electrode," Microchimica Acta, vol. 173, no. 1-2, pp. 157-163, 2011.

[32] M. Mazloum-Ardakani, H. Beitollahi, B. Ganjipour, H. Naeimi, and M. Nejati, "Electrochemical and catalytic investigations of dopamine and uric acid by modified carbon nanotube paste electrode," Bioelectrochemistry, vol. 75, no. 1, pp. 1-8, 2009.

[33] A. J. Bard and L. R. Faulkner, Electrochemical Methods: Fundamentals and Applications, John Wiley \& Sons, New York, NY, USA, 1980.

[34] J. Gohy, S. Creutz, M. Garcia, B. Mahltig, M. Stamm, and R. Jérôme, "Aggregates formed by amphoteric diblock copolymers in water," Macromolecules, vol. 33, no. 17, pp. 6378-6387, 2000.

[35] M. Borsari, M. Bellei, C. Tavagnacco, S. Peressini, D. Millo, and G. Costa, "Redox thermodynamics of cytochrome $\mathrm{c}$ in mixed water-organic solvent solutions," Inorganica Chimica Acta, vol. 349, pp. 182-188, 2003.

[36] Y. Hu, N. Hu, and Y. Zeng, "Electrochemistry and electrocatalysis with myoglobin in biomembrane-like surfactant-polymer $2 \mathrm{C}_{12} \mathrm{~N}^{+} \mathrm{PA}^{-}$composite films," Talanta, vol. 50, no. 6, pp. $1183-$ $1195,2000$.

[37] H. R. Zare, N. Nasirizadeh, M. Mazloum-Ardakani, and M. Namazian, "Electrochemical properties and electrocatalytic activity of hematoxylin modified carbon paste electrode toward the oxidation of reduced nicotinamide adenine dinucleotide (NADH)," Sensors and Actuators B: Chemical, vol. 120, no. 1, pp. 288-294, 2006.

[38] F. J. Verbaan, C. Oussoren, I. M. van Dam et al., "The fate of poly(2-dimethyl amino ethyl)methacrylate-based polyplexes after intravenous administration," International Journal of Pharmaceutics, vol. 214, no. 1-2, pp. 99-101, 2001.

[39] B. A. Springer, S. G. Sligar, A. Bellelli, G. Antonini, and M. Brunori, "Transient myogl obin of the reaction of cyanide with ferrous," The Journal of Biological Chemistry, vol. 265, no. 31, pp. 18898-18901, 1990.

[40] G. Battistuzzi, M. Borsari, L. Loschi, and M. Sola, "Redox properties of the basic blue protein (plantacyanin) from spinach," Journal of Inorganic Biochemistry, vol. 69, no. 1-2, pp. 97-100, 1998.

[41] E. V. Ivanova and E. Magner, "Direct electron transfer of haemoglobin and myoglobin in methanol and ethanol at didodecyldimethylammonium bromide modified pyrolytic graphite electrodes," Electrochemistry Communications, vol. 7, no. 4, pp. 323-327, 2005.

[42] E. T. Smith, L. D. Odom, J. A. Awramko, M. Chiong, and J. Blamey, "Direct electrochemical characterization of hyperthermophilic Thermococcus celer metalloenzymes involved in hydrogen production from pyruvate," Journal of Biological Inorganic Chemistry, vol. 6, no. 3, pp. 227-231, 2001.

[43] G. Batfistuzzi, M. Borsari, L. Loschi, and M. Sola, "Redox thermodynamics, acid-base equilibria and salt-induced effects for the cucumber basic protein. General implications for bluecopper proteins," Journal of Biological Inorganic Chemistry, vol. 2, no. 3, pp. 350-359, 1997.

[44] V. Reipa, M. J. Holden, M. P. Mayhew, and V. L. Vilker, “Temperature dependence of the formal reduction potential of putidaredoxin," Biochimica et Biophysica Acta, vol. 1459, no. 1, pp. 1-9, 2000.

[45] H. Gu, A. Yu, and H. Chen, "Direct electron transfer and characterization of hemoglobin immobilized on a au colloidcysteamine-modified gold electrode," Journal of Electroanalytical Chemistry, vol. 516, no. 1-2, pp. 119-126, 2001.

[46] Q. Wang, G. Lu, and B. Yang, "Direct electrochemistry and electrocatalysis of hemoglobin immobilized on carbon paste electrode by silica sol-gel film," Biosensors and Bioelectronics, vol. 19, no. 10, pp. 1269-1275, 2004.

[47] J. F. Gohy, S. Antoun, and R. Jérôme, "pH-dependent micellization of poly(2-vinylpyridine)-block-poly((dimethylamino)ethyl methacrylate) diblock copolymers," Macromolecules, vol. 34, no. 21, pp. 7435-7440, 2001.

[48] D. Eisenberg, R. M. Weiss, T. C. Terwilliger, and W. Wilcox, "Hydrophobic moments and protein structure," Faraday Symposia of the Chemical Society, vol. 17, pp. 109-120, 1982.

[49] D. Stigter, D. O. V. Alonso, and K. A. Dill, "Protein stability: electrostatics and compact denatured states," Proceedings of the National Academy of Sciences of the United States of America, vol. 88, no. 10, pp. 4176-4180, 1991.

[50] K. Qiao, H. Liu, and N. Hu, "Layer-by-layer assembly of myoglobin and nonionic poly(ethylene glycol) through iondipole interaction: an electrochemical study," Electrochimica Acta, vol. 53, no. 14, pp. 4654-4662, 2008.

[51] G. Ladam, P. Schaaf, F. J. G. Cuisinier, G. Decher, and J. Voegel, "Protein adsorption onto auto-assembled polyelectrolyte films," Langmuir, vol. 17, no. 3, pp. 878-882, 2001. 

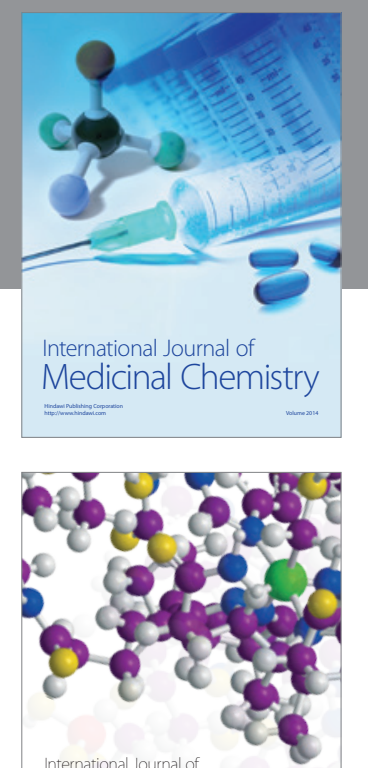

\section{Carbohydrate} Chemistry

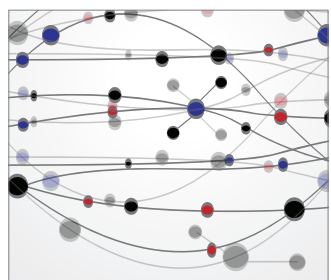

The Scientific World Journal
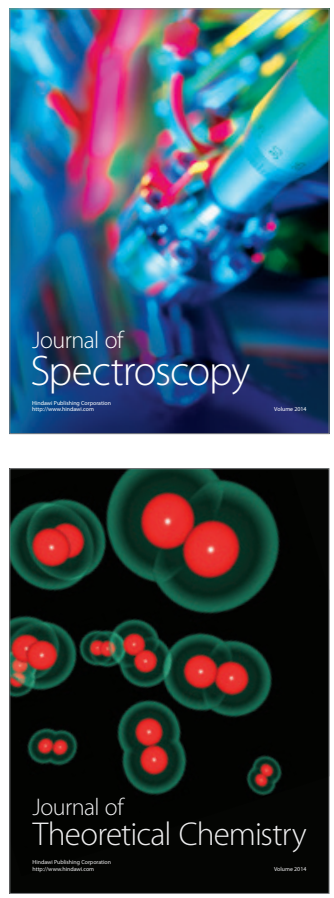
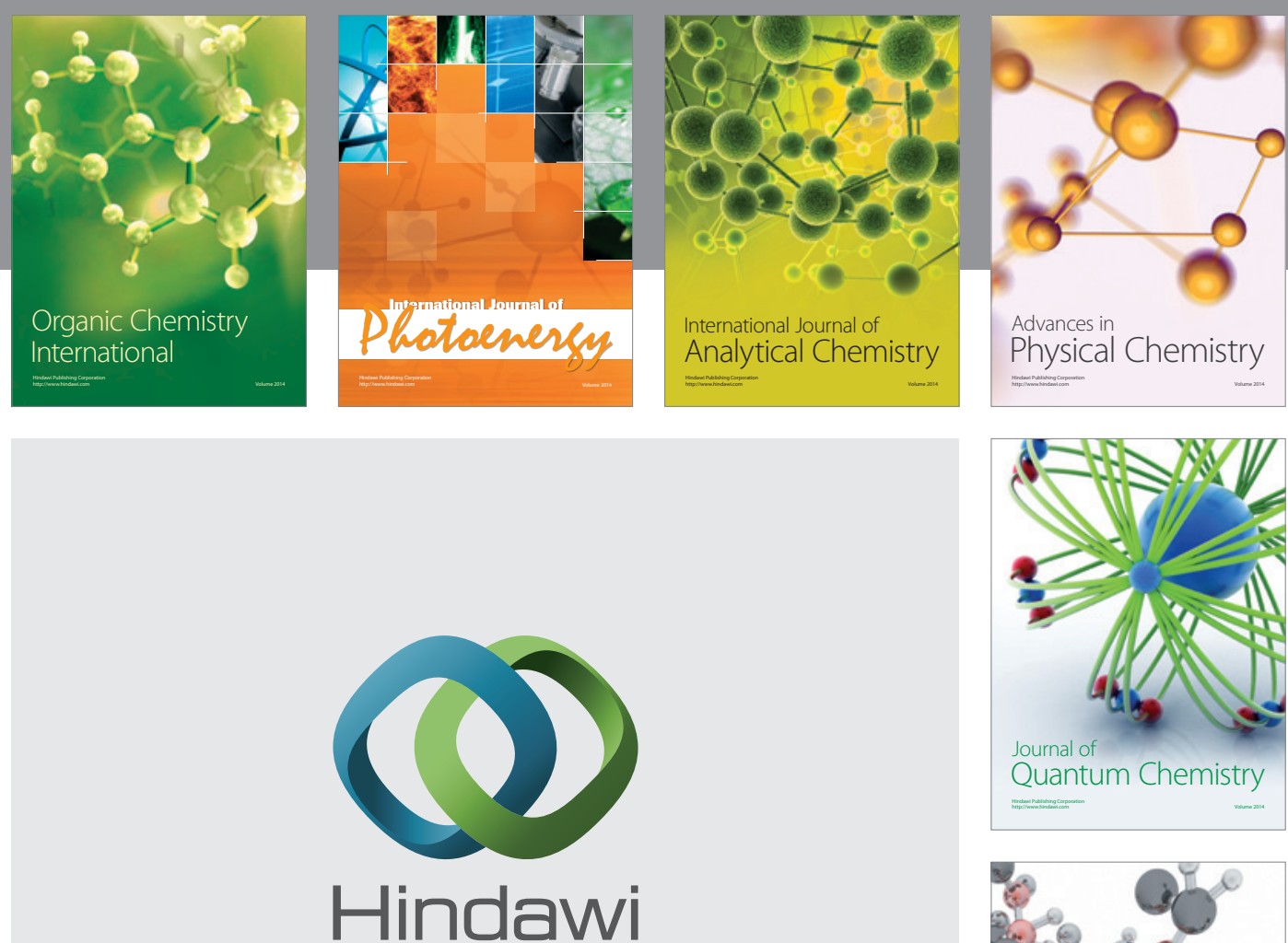

Submit your manuscripts at

http://www.hindawi.com

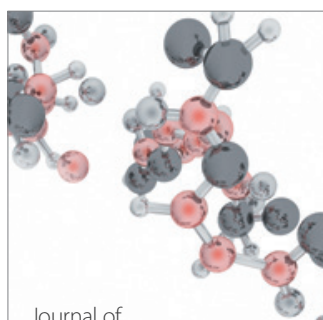

Analytical Methods

in Chemistry

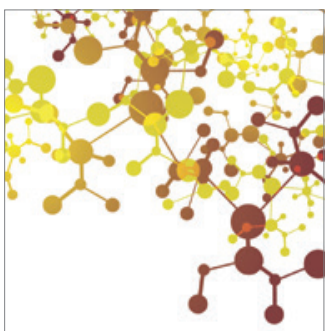

Journal of

Applied Chemistry

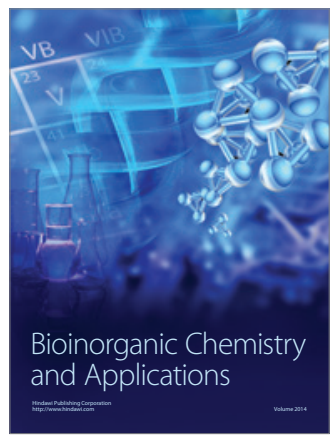

Inorganic Chemistry
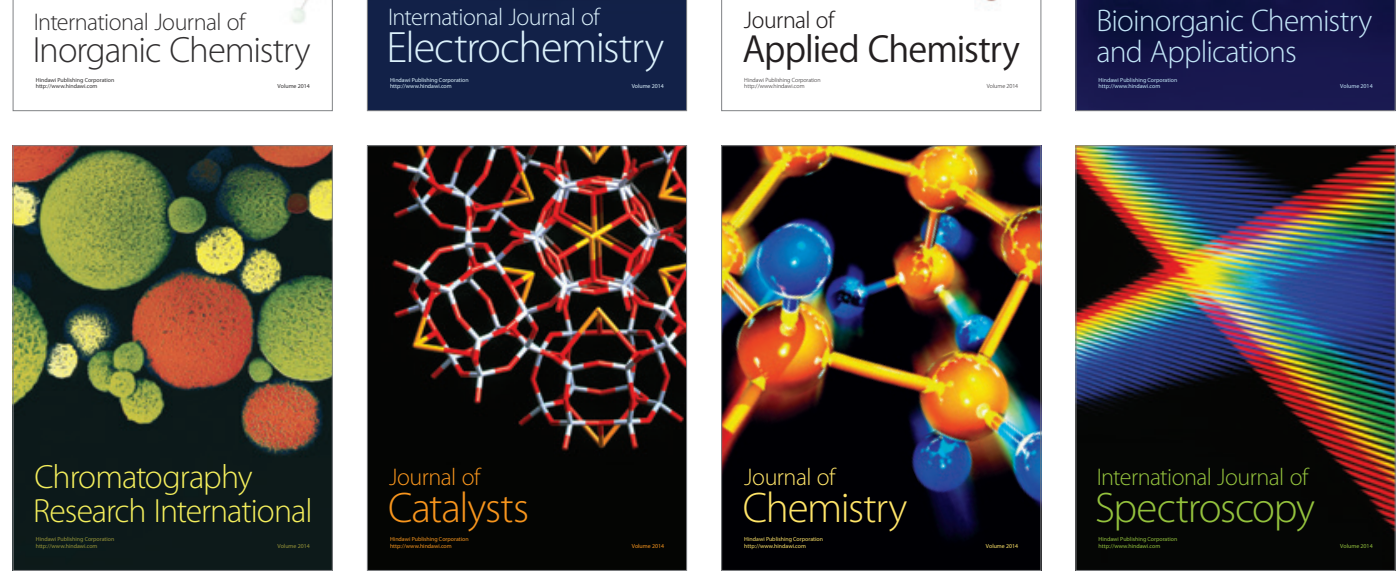